\title{
Premature mortality attributable to smoking among Tunisian men in 2009
}

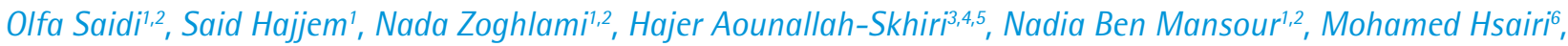 \\ Habiba Ben Romdhane'2, Julia A. Critchley', Dhafer Mallouche ${ }^{8}$, Martin O'Flaherty9 ${ }^{9}$ Radhouane Fakhfakh',10
}

\begin{abstract}
INTRODUCTION Tobacco smoking is a significant public health threat in the world, a risk factor for many diseases, and has been increasing in prevalence in many developing countries. In this study, we aimed to estimate the burden of premature deaths attributable to smoking among Tunisian men aged 35-69 years in 2009.

METHODS The number of deaths attributable to smoking was estimated using the population attributable risk fraction method. Smoking prevalence was obtained from a nationally representative survey. Causes of death were obtained from the registry of the National Public Health Institute. Relative risks were taken from the American Cancer Society Prevention Study (CPS-II).

RESULTS Total estimated premature deaths attributable to smoking among men in Tunisia were 2601 (95\% CI: 2268-2877), accounting for 25\% (95\% CI: 23.3-26.6) of total male adult mortality. Cancer, cardiovascular and respiratory diseases were the major causes of premature deaths attributable to smoking with 1272 (95\% CI: 1188-1329), 966 (95\% CI: 779-1133) and 364 (300-415) deaths, respectively.

concLusions Tobacco smoking is highly relevant and is related to substantial premature mortality in Tunisia, around double that estimated for the region as a whole. This also has not decreased over the past 20 years. Urgent actions are needed to reduce this pandemic.
\end{abstract}

\author{
AFFILIATION \\ 1 National Institute of Public Health, \\ Ministry of Health, Tunis, Tunisia \\ 2 Research Laboratory of Epidemiology \\ and Prevention of Cardiovascular \\ Diseases, Faculty of Medicine, University \\ Tunis El Manar, Tunis, Tunisia \\ 3 National Health Institute, Tunis, Tunisia \\ 4 Faculty of Medicine of Tunis, University \\ of Tunis El-Manar, Tunis, Tunisia \\ 5 The SURVEN (Nutrition Surveillance \\ and Epidemiology in Tunisia) Research \\ Laboratory, National Institute of \\ Nutrition and Food Technology, Tunis, \\ Tunisia \\ 6 Salah Azaiez Institute, Tunis, Tunisia \\ 7 Division of Population Health Sciences \\ and Education, St George's, University of \\ London, London, United Kingdom \\ 8 National Institute of Statistics and \\ Data Analysis, Tunis, Tunisia \\ 9 Department of Public Health and \\ Policy, University of Liverpool, Liverpool, \\ United Kingdom \\ 10 Unit of Research in Tobacco \\ Epidemiology and Control, Tunis, Tunisia \\ CORRESPONDENCE TO \\ Olfa Saidi. National Institute of Public \\ Health, Ministry of Health, Khartoum, \\ 1002, Tunis, Tunisia. E-mail: olfa.saidi@ \\ yahoo.fr \\ ORCID ID: https://orcid.org/0000-0001- \\ 5206-5736 \\ KEYWORDS \\ premature mortality, tobacco use, Tunisia
}

Received: 31 December 2018

Revised: 12 May 2019

Accepted: 28 September 2019

\section{INTRODUCTION}

Tobacco smoking has been estimated to be the second leading risk factor for death from all causes ${ }^{1-3}$, and it is the leading cause of preventable death (death at ages $<70$ years) in the world. According to the World Health Organization (WHO), tobacco use results in about 6 million deaths per year and this number will increase to more than 8 million per year 
by 2030 . More than $80 \%$ of those deaths will occur in low- and middle-income countries ${ }^{4}$, and many at early ages. The number of premature deaths (death at ages 30-69 years) was estimated at 4.83 million in 2000. Ezzati et al. ${ }^{3}$ estimated that only half of these deaths were registered in developing countries. The number of smoking-attributable deaths will increase considerably in these countries during the next few decades $^{3}$. In 2010, 8.4\% of the worldwide burden of diseases in men were attributed to tobacco smoking (including secondhand smoke), which made smoking the leading risk factor for death in men, while this proportion was $3.7 \%$ in women (fourth highest risk factor $)^{5}$. According to the Global Burden of Disease group, smoking was the fourth most crucial risk factor in terms of Disability-Adjusted Life Years (DALYs) after dietary risks, high blood pressure and high body mass index ${ }^{6}$, in Tunisia.

In many developed countries, the proportion of deaths attributed to smoking increased from $10.3 \%$ to $22.3 \%$ in men, and from $0.7 \%$ to $8.1 \%$ in women between 1955 and $2000^{7}$. In Tunisia, smoking prevalence in men has been very high for some time. In 1997, 30.5\% of adults were current smokers ( $55.8 \%$ in men and $5.3 \%$ in women), while more recent studies have confirmed that these smoking rates remain broadly constant in men $(55.2 \%)^{8,9}$. The burden of deaths attributable to smoking in men in Tunisia is hence likely to be high, but no estimate of this has been made since $1997^{10,11}$. The purpose of our study was to estimate the burden of premature deaths attributable to smoking among Tunisian men aged 35-69 years in 2009.

\section{METHODS}

The number of deaths was estimated using the
WHO methodology, which requires data on smoking prevalence, causes of deaths, population size and relative risks ${ }^{12}$ (Table 1 ).

\section{Smoking prevalence}

Smoking prevalence was obtained from the Epidemiological Transition and Health Impact in North Africa (TAHINA) survey. This was conducted in Tunisia in 2005 and included a nationally representative sample of 8007 individuals, aged 35-70 years ${ }^{13}$. 'Smoker' was defined as someone who reported smoking cigarettes daily for at least the month previous to the survey. 'Former smokers' were defined as adults who have smoked in their lifetime but report that they do not currently smoke. We assumed that smoking prevalence in 2009 would have been approximately the same as in 2005 . This assumption seems reasonable since smoking prevalence in adult men has remained mostly constant for the past ten years ${ }^{9}$.

\section{Causes of death}

Tunisian population estimates and number of deaths (distributed by age and sex) were obtained from the National Institute of Statistics ${ }^{14}$; while causes of death in 2009 were obtained from the Tunisian causes of death surveillance system (National Institute of Public Health, Ministry of Public Health), which uses the international death certificate model. Causes of death were coded according to the 10th revision of International Classification of Diseases (ICD10), using the STYX Software ${ }^{15}$. All deaths are recorded in Tunisia, and cause of death confirmed by a clinician is available for about $50 \%$ of the total. Based on the ANACONDA tool applied to Tunisian data in 2013, the weighted scores of the quality of cause of death

Table 1. Population sizes, number of deaths and smoking prevalence in men aged 35-69 years in Tunisia, 2009

\begin{tabular}{|c|c|c|c|c|c|}
\hline $\begin{array}{l}\text { Age group } \\
\text { (years) }\end{array}$ & Von smokers & Former smokers" & Current smokers & $\begin{array}{l}\text { Population } \\
\text { (1000) }\end{array}$ & $\begin{array}{c}\text { Deaths ** } \\
\text { n }\end{array}$ \\
\hline $35-39$ & 26.2 & 14.7 & 59.1 & 347 & 587 \\
\hline $40-44$ & 29.8 & 17.8 & 52.5 & 340 & 809 \\
\hline $45-49$ & 29.0 & 18.4 & 52.6 & 320 & 980 \\
\hline $50-54$ & 30.0 & 26.5 & 43.4 & 280 & 1546 \\
\hline $55-59$ & 21.6 & 31.3 & 47.1 & 208 & 1937 \\
\hline $60-64$ & 34.9 & 25.7 & 39.4 & 138 & 1977 \\
\hline $65-69$ & 35.5 & 37.3 & 27.3 & 122 & 2613 \\
\hline Total & 29.0 & 22.3 & 48.7 & 1756 & 10449 \\
\hline
\end{tabular}

Sources: * TAHINA Survey, ${ }^{* *}$ National Institute of Statistics. 
reporting, quality of age and sex reporting, the level of cause-specific detail available, are 72.2, 91.3 and 90.3 , respectively ${ }^{16}$.

We assumed that the causes of death by age were the same amongst those deaths with and without a classified cause. We applied the per cent of causes of deaths by gender and age groups to the total deaths registered in Tunisia. Premature mortality was defined as deaths occurring in the age group 35-69 years.

\section{Population data}

The Tunisian male population aged $\geq 35$ years was obtained from Tunisian National Institute of Statistics for 2009. In 2009, the Tunisian population was approximately 10 million, and there were 1.756 million men aged $35-69$ years $(33.7 \%$ of the total population of men). In this same year, there were 10449 deaths among men aged 35-69 years $^{14}$.

\section{Relative risks and mortality attributable to smoking}

Relative risks for specified causes of death among both current and former smokers of cigarettes, for men aged $\geq 35$ years, were taken from the American Cancer Society Prevention Study (CPS-II) ${ }^{17}$ (Table 2).

The number of deaths was estimated using population attributable risk fraction, by specific causes and age groups, based on Levin's formula ${ }^{18}$. Calculations were performed in MS Excel (Table 2). For sensitivity analyses, we used the upper and lower bounds of the $95 \%$ confidence intervals (CIs) for the prevalence of current and former smoking (from our own TAHINA surveys) and upper and lower values for relative risk (obtained from the US CPS-II dataset).

\section{RESULTS}

In 2009 , the crude mortality rate was 595 per 100000 among men aged 35-69 years. Figure 1 summarizes the leading causes of premature mortality among men in Tunisia, which were lung cancer (64 per 100000) followed by chronic heart diseases (60 per 100000 ) and cerebrovascular disorders (44 per 100000). The estimated number of premature deaths attributable to smoking among men was 2601 (95\% CI: 2268-2877), corresponding to $25 \%$ (95\% CI: $23.3-26.6$ ) of the total number of premature deaths for men (Figure 2).

Table 2. Mortality attributable to smoking in men in Tunisia, 2009

\begin{tabular}{|c|c|c|c|c|c|c|}
\hline \multirow[t]{2}{*}{ Discases } & \multirow[t]{2}{*}{$\%$} & \multirow[t]{2}{*}{ Deaths } & \multirow{2}{*}{$\begin{array}{l}\text { Current } \\
\text { smoker } \\
\text { RR }\end{array}$} & \multirow{2}{*}{$\begin{array}{l}\text { Former } \\
\text { smoker } \\
\text { RR }\end{array}$} & \multirow{2}{*}{$\begin{array}{l}\text { Smoking } \\
\text { attributable } \\
\text { mortality } \\
\text { n (95\% CI) }\end{array}$} & \multirow{2}{*}{$\begin{array}{l}\text { Proportion } \\
\text { attributable } \\
\text { n }\left(95^{\circ} \% \text { CI }\right)\end{array}$} \\
\hline & & & & & & \\
\hline \multicolumn{7}{|l|}{ Cardiovascular } \\
\hline Chronic heart & 10.1 & 1057 & 1.94 & 1.41 & $375(327-418)$ & $35.4(30.9-39.5)$ \\
\hline Cerebrovascular & 7.4 & 777 & 2.24 & 1.29 & $311(236-378)$ & $40.1(30.3-48.6)$ \\
\hline Other circulatory & 0.5 & 53 & 4.06 & 2.33 & $34(29-39)$ & $64.1(53.9-72.2)$ \\
\hline Other heart & 7.2 & 752 & 1.85 & 1.32 & 246 (188-299) & $32.7(24.9-39.7)$ \\
\hline All & 25.3 & 2639 & - & & 966 (779-1133) & - \\
\hline \multicolumn{7}{|l|}{ Respiratory } \\
\hline $\begin{array}{l}\text { Chronic obstructive } \\
\text { pulmonary }\end{array}$ & 2.7 & 281 & 9.65 & 8.75 & $241(226-252)$ & $85.6(80.3-89.5)$ \\
\hline Other & 3.1 & 325 & 1.99 & 1.56 & $123(74-164)$ & $37.8(22.7-50.4)$ \\
\hline All & 5.8 & 606 & - & & $364(300-415)$ & - \\
\hline \multicolumn{7}{|l|}{ Cancers } \\
\hline Lip, oral cavity, pharynx & 1.0 & 105 & 27.48 & 8.80 & $98(87-102)$ & $93.6(82.7-97.6)$ \\
\hline Esophagus & 0.3 & 36 & 7.60 & 5.83 & $29(23-32)$ & $81.1(64.1-90.2)$ \\
\hline Pancreas & 1.1 & 120 & 2.14 & 1.12 & $44(25-60)$ & $36.8(20.5-50.16)$ \\
\hline Larynx & 0.3 & 27 & 10.48 & 5.24 & $23(16-26)$ & $84.8(58.8-94.63)$ \\
\hline Lung & 10.7 & 1118 & 22.36 & 9.36 & $1034(1012-1052))$ & $92.5(90.5-94.0)$ \\
\hline Kidney & 0.0 & 0 & 2.95 & 1.95 & 0 & - \\
\hline Bladder, other urinal & 0.8 & 83 & 2.86 & 1.90 & $44(26-57)$ & $52.5(31.5-67.8)$ \\
\hline All & 14.3 & 1490 & & & 1272 (1188-1329) & - \\
\hline All causes & & 4735 & & & 2601 (2268-2877) & \\
\hline
\end{tabular}


Figure 1. Mortality rates per 100000 by causes among men aged 35-69 years in 2009

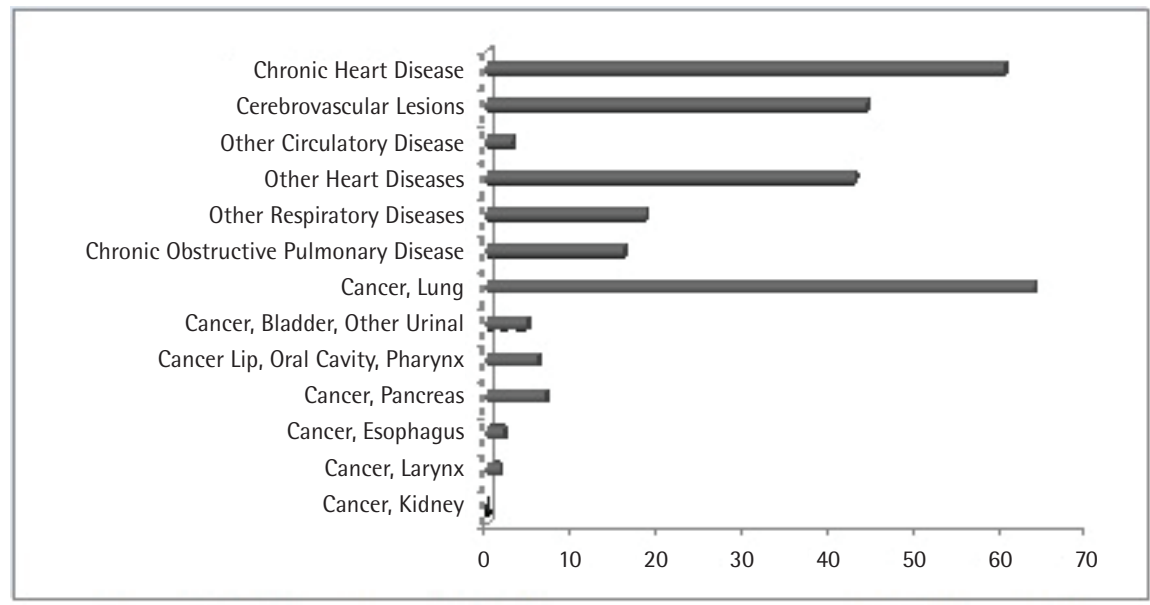

Sources: National Institute of Statistics and National Public Health Institute, Tunisia.

Figure 2. Deaths attributable to smoking among men aged 35-69 years in Tunisia in 2009

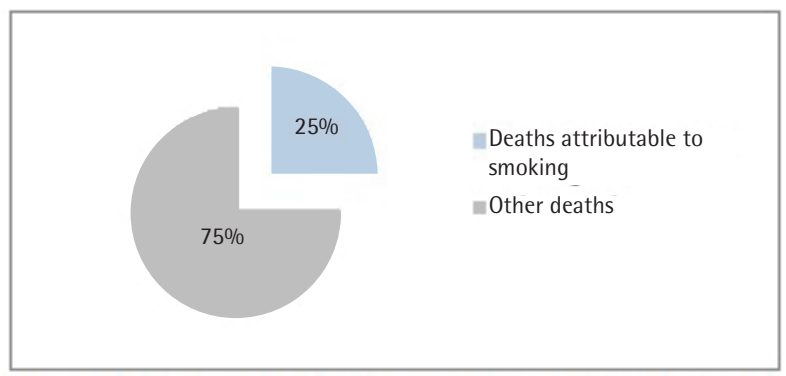

Cancer, cardiovascular disease and respiratory diseases were the major causes of premature death attributable to smoking accounting for 1272 (95\% CI: 1188-1329), 966 (95\% CI: 779-1133) and 364 (95\% CI: 300-415) deaths, respectively [48.9\% (95\% CI: $46.2-51.7)$, $37.1 \%$ (95\% CI: $34.4-40.4)$ and $14.0 \%$ (11.8-16.2)], as outlined in Table 2.

\section{Deaths attributable to smoking applying a sensitivity analysis (minimum-maximum)}

In 2009, 93.6\% (95\% CI: 82.7-97.6) of deaths caused by lip, oral cavity and pharynx cancers among men aged 35-64 years were attributable to smoking. Lung cancer had a high attributable risk associated with smoking among men [92.5\% (95\% CI: 90.5-94.0) of lung cancer deaths], the chronic heart disease [35.4\% (95\% CI: 30.9-39.5) of chronic heart disease deaths], cerebrovascular disorders [40.1\% (95\% CI: 30.3-48.6) of cerebrovascular disorders deaths] and chronic obstructive pulmonary disease [85.6\%
(95\% CI: 80.3-89.5)]. These diseases accounted for approximately $76.0 \%$ of total premature deaths attributable to smoking among men (Table 2).

\section{DISCUSSION}

This study showed that tobacco smoking in 2009 was responsible for about a quarter (2601 deaths) of premature deaths among Tunisian men. This could well confirm the propagation of the tobacco epidemic for men in Tunisia, referring to the Lopez et al. ${ }^{19}$ propagation model of tobacco use epidemic. A recent study advocates considering the tobacco epidemic separately for men and women, particularly in developing countries ${ }^{20}$, since the factors that lead to the start and continuation of cigarette smoking and tobacco use may be different for women than for men, and may also differ between developed and developing countries. However, in fact, the smoking status of women in Tunisia seems to be almost similar to that in Western countries during the middle of 20 th century 
with a substantial decrease in societal and cultural prohibition of cigarette smoking among women.

These estimates for 2009 were slightly lower than the previous ones of 1997 in Tunisia reported by Fakhfakh et al. ${ }^{10}$ who estimated that 6435 deaths occurred because of tobacco smoking in adults, amounting to $22 \%$ of total male deaths. However, the comparison of the two studies must be interpreted with caution due to methodological differences. The earlier study used the distribution of deaths by causes published by WHO in 1998 since the Tunisian information system on causes of death was not available at that time. Moreover, the earlier study included younger men aged $>25$ years, and all tobacco types (the use of other types of tobacco in Tunisia is about $1.5 \%)^{10}$. Nevertheless, our calculated proportion of smoking-attributable mortality was over twice that estimated by WHO for the Eastern Mediterranean region ( $12 \%$ for adult men), and it also exceeds that of China (12.9\% among men $)^{21}$, but not of western countries such France (33\%). Our estimate is close to some low- and middle-income countries such as India (20\% for men aged $30-69$ years in 2010) $)^{12,22,23}$.

Our results established that the leading causes of premature deaths from smoking were cancers, cardiovascular diseases and respiratory diseases. This is in line with findings from other studies, e.g. US in $2004^{24}$. Ezzati and Lopez ${ }^{3}$ also estimated that lung cancer was the disease with the highest fraction attributable to smoking worldwide in 2000. Almost three quarters $(71.0 \%)$ of all lung cancers or 0.85 million deaths $(79.0 \%$ or 0.69 million deaths among men and $48 \%$ or 0.16 million deaths among women) were attributable to smoking ${ }^{7}$. Thus, lung cancer mortality is the most specific indicator of tobacco smoking effects on health at the population level ${ }^{25}$. Cancer is the second leading cause of death globally, with about $70 \%$ occurring in low- and middle-income countries $^{26}$. The most common is lung cancer ${ }^{27}$. Due to reduced survival, the main burden of lung cancer is due to premature mortality rather than long-term illness. Lung cancer was the leading cause of cancerrelated premature mortality among males $(20 \%)^{28}$.

In comparison, in Eastern Morocco, lung cancer ranked the fourth most common cancer, accounting for $7.5 \%$ of total cancers and the most frequent malignancy with $19 \%$ of male cancers ${ }^{29}$. In Algeria, lung cancer is the sixth most common type of cancer
$(2.8 \%)$, and it is the most prevalent cancer in males representing $19.9 \%$ of cases $^{30}$.

About one-third of deaths from cancer are due to the 5 leading behavioral and dietary risks: tobacco use is the most critical risk factor for cancer and is responsible for approximately $22 \%$ of cancer deaths ${ }^{31}$. The mortality rate of deaths from lung cancer almost doubled from 34.8 per 100000 to 58.8 per 100000 among Tunisian men between 1997 and 2009 (reflecting the alarming situation of mortality and morbidity related to tobacco use in Tunisia) ${ }^{9}$. Unless steps are taken to reduce cigarette smoking, the coming decades will experience a significant increase in smoking related mortality and morbidity. Consequently, the economic burden will be high both for the community and also for many of the poorer households ${ }^{32}$. Since tobacco-induced diseases such as cancers and cardiovascular diseases are costly, out-ofpocket expenditure on health care is high in Tunisia.

In 2010, Tunisia adopted WHO Framework Convention on Tobacco Control, and a strategy was implemented in 2009, with clear goals, but still modest results, due to difficulties with implementation ${ }^{33}$. Since around 1992, several anti-smoking measures commenced in Tunisia including information campaigns and passing of an anti-smoking law to restrict smoking in public places; a decrease in tobacco sales has been observed but no decrease in smoking prevalence. It is thought that more smokers are purchasing cigarettes illegally, with substantial increases in tobacco smuggling due to political and security problems in Tunisia over the past three years. Moreover, smoking cessation interventions should be more targeted to high-risk groups to be more effective, such as young smokers and females, where smoking prevalence trends are highly worrisome ${ }^{34,35}$.

In this study, reliable data were used. Mortality data were obtained from registry of deaths collected by the other estimates, e.g. those produced by WHO EMRO rely on estimated mortality obtained from other countries with similar standards of living and development in the Region. This paper is the first to use Tunisian data from the national registry that records the death certificates. A recent assessment by WHO estimated that this mortality database was $87 \%$ accurate $^{36}$. Demographic information was provided from the census data while the relative risks were obtained from CPS-II, an extensive prospective cohort 
study, used in the majority of studies on smokingattributable mortality carried out in both developed and developing countries ${ }^{37}$. CPS-II relative risks were calculated in a smoking population consuming on average 20 cigarettes per $\mathrm{day}^{7}$, which is similar to the Tunisian context (the average daily consumption per men was $18 \pm 9$ cigarettes in $1997^{8}$ and $20 \pm 12$ in $\left.2005^{13}\right)$. Applying CPS-II relative risks is considered appropriate in the absence of extensive prospective studies from Tunisia or the Middle East and North Africa region (MENA region).

\section{Strengths and limitations}

The key strengths of this analysis include the nationally representative data collected through TAHINA. Conversely, this study had some limitations. The first is related to the fact that in this article, smoking prevalence excluded secondhand smoke and other types of tobacco use, especially waterpipe and chewing tobacco. These types of tobacco use are relatively common in Tunisia ${ }^{38}$, but their health impacts and relative risks poorly studied and documented ${ }^{39}$. This exclusion suggests that the estimate of tobacco attributable mortality may be even higher in Tunisia. Most studies of mortality attributable to tobacco have only included cigarette smoking and ignored other types of tobacco use, except in the Indian Subcontinent where smokeless tobacco is particularly common ${ }^{40}$. Another limitation of this study is that we excluded liver and stomach cancers in our estimation. Latency may be a limitation, as smoking in men in Tunisia has been constant for some time and all causes of death that might possibly be attributed to smoking were not included.

Another limitation is that we focused on only mortality attributable to smoking in men, excluding women, even though female smoking is thought to be increasing. Unfortunately, there are no data considered sufficiently reliable to estimate the prevalence of smoking in Tunisian women. The current national estimate of $4 \%$ is likely to be a substantial underestimate ${ }^{6}$. This is because female smoking is still culturally prohibited ${ }^{13}$. For example, the association between lung cancer in women and tobacco smoking differs between countries. The highest estimates come from North American studies, with relative risk near 20 , though the lowest come from Asian studies ${ }^{24}$.

\section{CONCLUSIONS}

Cigarette consumption in Tunisian men was responsible for 2601 deaths in 2009 , one-quarter of premature deaths. These estimates of premature mortality have significant public health implications. The tobacco epidemic in Tunisia is firmly established and results in an unavoidable burden of morbidity and mortality in Tunisia. In regard to this alarming situation, effective interventions to reverse this trend were already taken a few years ago; Tunisian decision-makers defined a strategy in 2009 to reduce smoking prevalence, tobacco control actions involving legislation, education at worksites and schools, and the implementation of outpatient smoking cessation programs in health centers, but this has not been enforced. Now, more focus must be given to stop the flow of new smokers, from population groups such as youth and females.

\section{REFERENCES}

1. Lopez AD, Mathers CD, Ezzati M, Jamison DT, Murray CJL. Global and regional burden of disease and risk factors, 2001: Systematic analysis of population health data. Lancet. 2006;367:1747-1757. doi:10.1016/s0140-6736(06)68770-9

2. Ezzati M, Lopez AD, Rodgers A, Vander Hoorn S, Murray CJL. Selected major risk factors for global and regional burden of disease. Lancet. 2002;360:1347-1360. doi:10.1016/s0140-6736(02)11403-6

3. Ezzati M, Lopez AD. Estimates of global mortality attributable to smoking in 2000. Lancet. 2003;362:847852. doi:10.1016/s0140-6736(03)14338-3

4. World Health Organization. Tobacco. http://www.who. int/mediacentre/factsheets/fs339/en/. Published 2013. Accessed June 2, 2014.

5. Lim SS, Vos T, Flaxman AD, et al. A comparative risk assessment of burden of disease and injury attributable to 67 risk factors and risk factor clusters in 21 regions, 1990-2010: a systematic analysis for the Global Burden of Disease Study 2010. Lancet. 2012;380:2224-2260. doi:10.1016/S0140-6736(12)61766-8

6. Institute for Health Metrics and Evaluation. Global burden of diseases, injuries, and risk factors study. In: GBD Profile: Tunisia. http://www.healthdata.org/sites/ default/files/files/country_profiles/GBD/ihme_gbd_ country_report_tunisia.pdf. Accessed June 2, 2014.

7. Peto R, Boreham J, Lopez AD, Thun M, Heath C. Mortality from tobacco in developed countries: indirect estimation from national vital statistics. Lancet. 1992;339:12681278. doi:10.1016/0140-6736(92)91600-d

8. Fakhfakh R, Hsairi M, Maalej M, Achour N, Nacef T. Tobacco use in Tunisia: behavior and awareness. Bull 
World Health Organ. 2002;80(5):350-356.

9. Saidi O, Ben Mansour N, O'Flaherty M, Capewell S, Critchley JA, Ben Romdhane H. Analyzing recent coronary heart disease mortality trends in Tunisia between 1997 and 2009. Plos One. 2013;8:e63202. doi:10.1371/journal.pone.0063202

10. Fakhfakh R, Hsairi M, Ben Romdhane H, Achour N. Mortality due to smoking in Tunisia in 1997 (in French). Tunis Med. 2001;79:408-412.

11. Fakhfakh R, Hsairi M, Achour N. Epidemiology and prevention of tobacco use in Tunisia: a review. Prev Med. 2005;40:652-657. doi:10.1016/j.ypmed.2004.09.002

12. World Health Organization. WHO Global Report: Mortality attributable to tobacco. https://www.who. int/tobacco/publications/surveillance/rep_mortality_ attributable/en/. Published 2012. Accessed June 16, 2014.

13. Research Laboratory of Epidemiology and Cardiovascular Diseases Prevention. Epidemiological Transition and Health Impact in North Africa. TAHINA Project Final Report. 2006.

14. National Institute of Statistics. Yearly Statistics Report: 2009. $N^{\circ}$ 52. Tunisia; 2010

15. National Public Health Institute. Deaths Registry, 2009. Tunisia; 2011.

16. Saidi O, et al. ANACONDA Results Tunisian data 2013. Training of trainers' capacity building workshop in methods of cause of death quality assessment (anaconda) and cause of death certification. Aswan, Egypt. 30 July-3 August 2017.

17. Office of the Surgeon General. Reducing the Health Consequences of Smoking: 25 years of progress (1989). http://profiles.nlm.nih.gov/ps/access/NNBBXS.pdf. Accessed May 7, 2014.

18. World Health Organization. Metrics: Population Attributable Fraction (PAF). Quantifying the contribution of risk factors to the Burden of Disease. http://www.who. int/healthinfo/global_burden_disease/metrics_paf/en/ index.html. Accessed June 23, 2014.

19. Lopez AD, Collishaw N, Piha T. A descriptive model of the cigarette epidemic in developed countries. Tob Control. 1994;3:242-247. doi:10.1136/tc.3.3.242

20. Thun M, Peto R, Boreham J, Lopez AD. Stages of the cigarette epidemic on entering its second century. Tob Control. 2012;21:96-101. doi:10.1136/tobaccocontrol-2011-050294

21. Gu D, Kelly TN, Wu X, et al. Mortality Attributable to Smoking in China. N Engl J Med. 2009;360:150-159. doi:10.1056/nejmsa0802902

22. Mulliss R, Brown P, Fiona A. What a waste: Premature deaths due to smoking - the picture in the South West. South West Public Health Observatory Bulletin; 2008.

23. Hill C, Laplanche A. Tabagisme et mortalité: aspects épidémiologiques. Département de Santé Publique, Institut Gustave Roussy, Villejuif. http:// beh.santepubliquefrance.fr/beh/2003/22_23/ beh_22_23_2003.pdf. Accessed April 17, 2014.

24. Office of the Surgeon General; Office on Smoking and Health. The Health Consequences of Smoking: A Report of the Surgeon General. Atlanta: Centers for Disease Control and Prevention; 2004.

25. Winkler V, Ng N, Tesfaye F, Becher H. Predicting lung cancer deaths from smoking prevalence data. Lung Cancer. 74;2011:170-177. doi:10.1016/j.lungcan.2011.02.011

26. GLOBOCAN 2012: Estimated Cancer Incidence, Mortality and Prevalence Worldwide in 2012 v1.0. IARC Cancer Base No. 11. Lyon, France: International Agency for Research on Cancer; 2013. https://publications.iarc. $\mathrm{fr} /$ Databases/Iarc-Cancerbases/GLOBOCAN-2012Estimated-Cancer-Incidence-Mortality-And-PrevalenceWorldwide-In-2012-V1.0-2012. Accessed December 31, 2018.

27. World Health Organization. Cancer. https://www.who. int/news-room/fact-sheets/detail/cancer. Published September 12, 2018. Accessed December 31, 2018.

28. Youlden DR, Cramb SM, Baade PD. The International Epidemiology of Lung Cancer: Geographical Distribution and Secular Trends. J Thorac Oncol. 2008;3. https://core. ac.uk/download/pdf/81969749.pdf. Accessed December $31,2018$.

29. Elidrissi Errahhali M, Elidrissi Errahhali M, Ouarzane M, Boulouiz R, Bellaoui M. Cancer incidence in eastern Morocco: cancer patterns and incidence trends, 2005-2012. BMC Cancer. 2017;17:587. doi:10.1186/s12885-017-3597-6

30. Benarba B, Meddah B, Hamdani H. Cancer incidence in North West Algeria (Mascara) 2000-2010: results from a population-based cancer registry. EXCLI J. 2014;13:709723. PMCID: PMC4464491.

31. GBD 2015 Risk Factors Collaborators. Global, regional, and national comparative risk assessment of 79 behavioural, environmental and occupational, and metabolic risks or clusters of risks, 1990-2015: a systematic analysis for the Global Burden of Disease Study 2015. Lancet. 2016;388(10053):1659-1724. doi:10.1016/S0140-6736(16)31679-8

32. Xin Y, Qian J, Xu L, Tang S, Gao J, Critchley J. The impact of smoking and quitting on household expenditure patterns and medical care costs in China. Tob Control. 2009;18:150-155. doi:10.1136/tc.2008.026955

33. National Program for Tobacco Control: Realities and perspectives. Tunisia: Direction of Health Care-Ministry of Health; 2009.

34. The Lancet NCD Action Group, The NCD Alliance. Priority actions for the non-communicable disease crisis. Lancet. 2011;377:1438-1447. doi:10.1016/S0140-6736(11)60393-0

35. Qiao Q, Tervahauta M, Nissinen A, Tuomilehto J. Mortality from all causes and from coronary heart disease related to smoking and changes in smoking during a 35-year follow-up of middle-aged Finnish men. Eur Heart J. 2000;21:1621-1626. doi:10.1053/euhj.2000.2151 
36. The League of Arab States. The First Meeting of Working on Civil Registration and Vital Statistics in the Arab Countries (CRVS). Cairo: 20-22 May 2014.

37. Pérez-Ríos M, Montes A. Methodologies used to estimate tobacco-attributable mortality: a review. BMC Public Health. 2008;8:22. doi:10.1186/1471-2458-8-22

38. Koubaa A, Trabelsi H, Masmoudi L, Triki M, Sahnoun Z, Zeghal K. Water pipe Tobacco Smoking and Cigarette Smoking: Comparative Analysis of the Smoking Effects on Antioxidant Status, Lipid Profile and Cardiopulmonary Quality in Sedentary Smokers Tunisian. International Journal of Pharmaceutical Science. 2013;2:51-57.

39. Giovino GA, Mirza SA, Samet JM et al. Tobacco use in 3 billion individuals from 16 countries: an analysis of nationally representative cross-sectional household surveys. Lancet. 2012;380:668-679. doi:10.1016/s0140-6736(12)61085-x

40. Wu F, Chen Yu, Parvez F et al. A Prospective Study of Tobacco Smoking and Mortality in Bangladesh. PLoS One. 2013;8(3):e58516. doi:10.1371/journal.pone.0058516
CONFLICTS OF INTEREST

The authors have completed and submitted the ICMJE Form for Disclosure of Potential Conflicts of Interest and none was reported.

\section{FUNDING}

There was no source of funding for this research.

AUTHORS' CONTRIBUTIONS

$\mathrm{RF}, \mathrm{MH}, \mathrm{JAC}$ and $\mathrm{OS}$ conceived the idea of the study. $\mathrm{RF}, \mathrm{MH}, \mathrm{SH}, \mathrm{OS}$, HAS, NBM and HBR assembled the datasets. OS, RF, MH, HAS, NBM, $\mathrm{HBR}, \mathrm{DM}, \mathrm{MO}$ and JAC wrote the first draft of the paper and finalized the manuscript. All authors contributed to the analysis, intellectual content, critical revisions to the drafts of the paper and approved the final version. $\mathrm{OS}$ is the guarantor.

PROVENANCE AND PEER REVIEW

Not commissioned; externally peer reviewed. 